\title{
Vencer o Tempo como uma Fotografia. Falação e Silêncio em "Elogio de Maria Teresa", de Ruy Belo
}

\author{
BiAgio D'ANGelo \\ Pontifícia Universidade Católica/São Paulo
}

RESUMO: PROPONHO AQUI INVESTIGAR AS RELAÇÕES ENTRE LITERATURA E ARTES VISUAIS POR MEIO DA LEITURA DE UMA LÍRICA DO POETA PORTUGUÊS RUY BELO, "ELOGIO DE MARIA TERESA", UM TEXTO PARADIGMÁTICO DA POÉTICA DA IMAGEM E DO VÍNCULO DESSA ÚLTIMA COM O TEXTO. APOIANDO-NOS EM ROLAND BARTHES, TENTAMOS MOSTRAR QUE A FOTOGRAFIA PODE SE CONVERTER NUMA PROPOSTA DE SIMULACRO SAGRADO, ÍCONE DA "MEMÓRIA", NO SENTIDO DE UM PASSADO QUE CONTINUA VIVO E UM PRESENTE DETERMINADO. COM EFEITO, A LITERATURA DE RUY BELO SE ENCARREGA DE DESVENDAR VAZIOS EM UMA EXPERIÊNCIA LIMINAR PORQUE A MEMÓRIA DA FOTOGRAFIA SEMPRE FALA A PARTIR DE UM OBJETO QUE NÃO É MAIS, A PARTIR DE UMA EXPERIÊNCIA DE MORTE.

ABSTRACT: IN THIS ARTICLE, I WOULD LIKE TO ANALYZE THE RELATIONS BETWEEN LITERATURE AND THE VISUAL ARTS, BY READING "ELOGIO DE MARIA TERESA", BY THE PORTUGUESE POET RUY BELO. THIS POEM REPRESENTS A PARADIGM IN THE POETICS OF IMAGE, PHOTOGRAPHY AND TEXT. DRAWING ESPECIALLY FROM ROLAND BARHES' S THEORY, I TRY TO SHOW THAT THE PHOTO BECOMES A PROPOSAL FOR A SACRED SIMULACRUM, A SACRED IMAGE, AN ICON OF MEMORY, IN THE SENSE OF A STILL LIVING PAST AND A DETERMINED, CIRCUMSTANCED PRESENT. ACTUALLY, RUY BELO'S LITERATURE OPENS HOLES, DISCLOSES BLANK SPACES, IN A LIMINAL EXPERIENCE: PHOTOGRAPHY'S MEMORY IS RELATED TO AN EXPERIENCE OF DEATH. MEMORY AN EXPERIENCE OF TRAUMA.

PALAVRAS-CHAVE: RELAÇÕES ENTRE LITERATURA E ARTES VIUAIS - FOTOGRAFIA MEMÓRIA - TRAUMA - MORTE

KEYWORDS: RELATIONS BETWEEN LITERATURE AND VISUAL ARTS - PHOTOGRAPHY MEMORY - TRAUMA - DEATH 
não seria yerdade porque me aparecem e desaparecem imagens vagas, recordações, pequenos farrapos sem sentido, um pouco como antes de começar a escrever um romance, quando filamentos de personagens principiam a cristalizar-se em filamentos de palavras e o plano do livro se constrói lentamente, ganhando nexo".

(António Lobo Antunes, Livro das crônicas)

"Who was Bellocq? A photographer. [...] Bellocq was a window looking out"

(Michael Ondaatje, Coming Through Slaughter)

O tema sobre as relações entre literatura e artes visuais é, notoriamente, vastíssimo. Os vínculos miméticos entre a fotografia e o texto literário são ainda mais evidentes e diversos trabalhos são dedicados à leitura da fotografia como narração. A técnica da fotografia influencia a escrita com uma intensidade sempre maior. Se por um lado, a fotografia, no seu formato digital, foi se transformando, com sempre maior intensidade, numa autêntica "instantânea", na qual se multiplicam ad libitum as "possibilidades" de fotografar (até mesmo quase fazendo desse gesto estético um procedimento instintivo), pelo outro, a fotografia, sempre à procura dos materiais da atualidade, pretende escrever a história do pormenor e do presente.

O que norteia nossa indagação deriva da questão se é possível resolver o problema da fugacidade existencial por meio de um artístico carpe diem fotográfico: fotografar cada aspecto e momento da vida para, mais tarde, poder finalmente recordar a história e, dela, em um momento sucessivo, manter a recordação.

A literatura utiliza o material iconográfico e a fotografia para reafirmar que pode construir a própria textualidade somente a partir da saturação da morte, da confusão caótica, da suspeita do vazio existencial. É justamente dentro desta gestualidade mortífera da literatura, que a escrita volta, por assim dizer, à sua funcionalidade originária para deixar, tanto ao leitor quanto ao observador, uma proposta provocadora, subversiva, desestabilizadora. E a foto quer ser uma "pro-vocação" às questões últimas do valor da História, bem como dos afetos que movem o Eu. 
A aspiração ao "lugar" duradouro, a uma "história" sem mentiras e enganos, a um "ideal" amiúde silenciado tece, paradoxalmente, uma trama temporal feita, ao contrário, de imagens e rapidez. A imagem é percebida, portanto, como emblema e sinal do imediato e do fugaz, do improviso e do vazio e, ao mesmo tempo, como desejo de recuperar um passado incrustado numa dimensão histórica que se conhece, talvez, ainda pouco e se deseja redescobrir.

Lois Parkinson Zamora e Wendy B. Faris propuseram uma leitura da história que pode ser aplicada também à imagem, à fotografia e à narrativa histórica, recorrendo à metáfora da fotografia como estratégia de simular o passado: "History is inscribed, often in detail, but in such a way that actual events and existing situations are not always privileged and are certainly not limiting: historical narrative is no longer chronicle but clairvoyance" (Zamora-Faris, 1995, p. 6. Grifo meu).

Certamente, qualquer foto ou qualquer sinal icônico descrevem uma história (que se relaciona com a História), mas, agora, já não como narração dos fatos transcorridos, mas como percepção profética - e, possivelmente, compreensão - de tudo o que foi passado.

O retorno à história e à sua procura de significação é, atualmente, uma das preocupações principais da produção cultural das últimas décadas. Segundo a interpretação que dá Fredric Jameson (1990, p. 130), tratar-se-ia de uma história incompleta, uma "história com buracos" ("history with holes"), uma "história perfurada" ("perforated history"), da qual o sujeito não apenas pede compreensão, mas enfrenta o problema: ele penetra nesses buracos históricos para indagar sobre aspectos tradicionalmente silenciados ou dissimulados, como a questão racial, a censura e a proibição, ou temas heterogêneos como a origem do conceito de nação, a miscigenação dos povos e as minorias pouco reconhecidas ou evitadas. Todavia, o que importa ao crítico norteamericano - e é também aquilo que interessa neste espaço - é prestar atenção àquilo que ele chama sinteticamente nostalgia film, ou seja, uma nostalgia das grandes narrações (e meta-narrações) que demonstraram o seu falimento e a sua inconsistência diante da complexidade do real. Filmes, imagens, fotografias, e todo o conjunto de mediações, que freqüentemente operaram com violência inaudita e raramente justificável, serviram para evidenciar e indicar as perversões culturais e políticas de sempre. Parkinson e Zamora comentam, nesse sentido, que "hallucinatory scenes and events, fantastic/phantasmago- 
ric characters are used [...] to indict recent political and cultural perversions" (Parkinson Zamora, 1995, p. 6). A imagem, então, não possui apenas uma natureza efêmera, mas, ao mesmo tempo, a pretensão de transformar em atualidade os eventos para depois julgá-los.

A mesma fotografia não é senão um fragmento, mas um fragmento que aspira à imagem completa, à objetividade narrativa, escreve Susan Sontag: "It drifts away into a soft abstract pastness, open to any kind of reading" (Sontag, 1977, p. 71). Uma lírica como Elogio de Maria Teresa, de Ruy Belo, representa um texto paradigmático da poética da imagem, da fotografia e do vínculo dessa última com o texto. A escrita e a fotografia tornaram-se necessidades estéticas, instrumentos potenciais que servem à compreensão da realidade como alteridade indecifrável. A realidade, de fato, se mostra sob o aspecto dos fragmentos, ausência de conclusão, incoerência que aguarda uma recomposição (que, justamente, revê as categorias antes mencionadas do possível e do provável). A coisa fotografada "reage", por assim dizer, com um surplus inimaginável, no sentido literal do termo, enquanto a intimidade da memória se mescla aos fantasmas, à poeira do tempo ao peso da história pessoal. Nessa lírica de Ruy Belo o outro já não se instaura tanto em uma totalidade perseguida, quanto numa perspectiva de morte e de declínio. A poesia é só uma andança aproximativa. Ela não explica, nem salva, nem permite a descoberta do outro. A imagem, como a poesia, longe de desenhar uma integridade apaziguadora, apresenta, ao interno de sua realidade sempre paradoxalmente aproximativa, vazios e pulsões catastróficas.

Eu que às vezes encontro sem saber porquê um simples não sei quê em estátuas retratos antigos de límpidas mulheres desconhecidas eu que de súbito à primeira vista me apaixono adolescentemente por essas mulheres mortas mas contemporâneas de um pobre poeta português do século vinte levadas até ele talvez por um discreto gesto às formas e às cores impresso por um homem que na arte encontrava a única razão de vida abro a pasta e deparo com o teu retrato um retrato de passe anos atrás tirado 
no sítio suburbano onde primeiro vivemos

e juntos suportámos com surpresa a solidão

de sermos dois e ela só vergar os ombros onde os dias nos poisavam

Conheço outros retratos teus onde também estás viva

um deles bem me lembro estava à minha espera em saint-malo

uma tarde ao voltar do monte saint michel

nesse verão bretão onde então procurava

justificação por mínima que fosse para a vida

numa das muitas fugas de mim próprio

que às vezes empreendo embora antecipadamente certo

de que só pela morte enfim me encontrarei comigo

com todos quantos verdadeiramente amei

alguns desconhecidos e alguns mesmo inimigos

sobretudo sedentos de justiça

de que depois somente de bem morto hei-de dispor daquela paz

que sempre apeteci mas nunca procurei

até por não ter tempo para isso nem sequer para saber

coisas simples como saber quem sou porque ao certo só sei

que muito mais passei naquilo em que fiquei

nem que fossem os filhos ou os versos

que fiquei muito mais naquilo onde passei

como passos na areia no inverno ou repentinas sensações

de me sentir de súbito sensivelmente bem

encher o peito de ar sentir-me vivo

São retratos diferentes de quem foste um breve instante

e nele floriste e apenas não murchaste

por haveres ficado um pouco mais em tais fotografias

Mas há em todos eles uma graça inesperada

a surpresa da corça ou restos dessa raça

que há em ti talvez um pouco mais que nas demais mulheres

expressão sempre surpreendente da surpresa

mesmo até para quem te conhece tão bem como eu te conheço

Se nuns mais do que noutros sem excepção desponta

a madrugada que era e é esse teu riso claro

quem primeiro falou de riso claro 
talvez houvesse ouvido a água quando corre sobre os seixos de um ribeiro

talvez a houvesse visto branca e fresca mas teve de inventar pra conquistar essa metáfora quando eu que te ouvi rir não fiz mais do que ouvir e sei que o som da água imita o teu sorriso Talvez dentro de séculos se não fale já de ti coisa aliás sem maior importância que a de não ter alguém deixado o teu retrato em qualquer dos museus esparsos pelo mundo Eu estarei morto e pouco poderei fazer por ti simples mulher da minha vida Mas isso não importa importa esta manhã este bar de milão onde olho o teu retrato enquanto espero o meu pequeno almoço saboreio as cervejas em jejum tomadas e começam de súbito a chegar aos meus ouvidos inesperados os primeiros acordes do concerto imperador Se um dia penso porventura te perder mulher simples recôndita e surpreendente sobre quem recaiu o peso do meu nome só então saberei quanto valias verdadeiramente Estás presente em mim como ninguém e sabes quão terrivelmente amei e amo outras mulheres além de ti além de minha mãe Mas tu tens o meu nome clara rilke tu trocaste a tua alegre vida irrequieta no único infeliz dos teus negócios por um poeta pobre velho e feio como eu Contigo aprendi coisas tão simples como a forma de convívio com o meu cabelo ralo e a diversa cor que há nos olhos das pessoas Só tu me acompanhaste súbitos momentos quando tudo ruía ao meu redor e me sentia só e no cabo do mundo 
Contigo fui cruel no dia a dia

mais que mulher tu és já hoje a minha única viúva

Não posso dar-te mais do que te dou

este molhado olhar de homem que morre

e se comove ao ver-te assim presente tão subitamente

Bons dias maria teresa até depois

preciso de tomar o meu pequeno almoço

a cerveja era boa mas é bom comer

como come qualquer homem normal

e me poupa ao perigo de até pela idade

me converter subitamente num sentimental

Nessa lírica, recontar a distância e o amor é fixar o que não é mais e o que é presente, porque é observado agora. Para o poeta, a superação do mal-estar existencial consista em aceitar a singularidade da realidade como experiência nostálgica de uma ausência à qual tudo conflui. A escrita - tanto literária, quanto fotográfica - apresenta um espaço ao interior do qual a morte ou a lembrança mortífera são regeneradas. É o efeito da literatura, onde se intui que, dentro dos mecanismos que movem o real, existe -como escreve Barthes - um punctum, uma ferida, uma ruptura, um fragmento ulterior, que, secretamente, remete a uma meta-natureza que representa o ponto mais alto da razão estética.

Essa ferida é a tensão constante que aparece na produção poética de Ruy Belo. Trata-se de uma tensão cujo punctum último, conclusivo se dá no silêncio: "O grande poeta - escreve Belo - é aquele que domina o silêncio (...) porque a verdade está no outro lado das coisas" (Belo, 1984, p. 56). Ruy Belo escolhe a densidade da imagem fotográfica ("abro a pasta e deparo com o teu retrato/ um retrato de passe anos atrás tirado/ no sítio suburbano onde primeiro vivemos/ e juntos suportámos com surpresa a solidão de sermos dois") porque enxerga nela uma "poética trágica", para referir-nos com as palavras de Ida Alves:

Embate entre a pulsão da vida e a pulsão da morte, afinal, a síntese da existência humana. Mas, nesse embate permanente que a arte manifesta, está a razão da escrita poética que é necessariamente um exercício do irreconciliável, uma 
tentativa sempre malograda de se aproximar por imagens do indizível (Alves, 2008, p. 251. Grifo nosso).

Com efeito, o efêmero da imagem é também seu paradoxo. A imagem permanece "para sempre", congela o instante, se coloca como desafio à realidade. Se a realidade é mutação, variação, incessante proposta de renovação, a fotografia com a perene oscilação entre a reprodução da realidade e seu significado enigmático "afirma" a existência do mundo fenomenológico e, ao mesmo tempo, "afirma" a "seleção" de um aspecto perceptível do mundo. A arte, mais tarde, incentivará este aspecto, partindo do detalhe (não da realidade abstrata) e construindo a passagem do real ao imaginário. «...Il s’agit ici de passages : du réel à l'imaginaire, du rêve à l'éveil, du monde des vivantes au monde des morts », escreve Leyla Perrone Moisés, num ensaio dedicado a Cortázar e Lautréamont, passando pelo suporte teórico de Benjamin. Esta passagem, esta "animação" - do real ao imaginário - é a essência ontológica da fotografia, que se manifesta somente aos olhos do artista, do observador, e revela, deste modo, a sua continuidade e a estrema funcionalidade: informação, representação, surpresa, significação como indicado por Roland Barthes em La chambre claire (1980).

O brilhante e melancólico estudo sobre a fotografia de Barthes representa uma extraordinária leitura poética da foto, que parece estar inspirada não apenas por um acontecimento histórico pessoal - a morte da mãe do autor (à qual são dedicadas as páginas mais comoventes do ensaio) -, mas também pela releitura imaginária do conto cortazariano Las babas del diablo. Com efeito, a sensação de "inauthenticité, parfois d'imposture" (Barthes, 2002, p. 30) que Barthes registra como experiência pessoal, é similar à reflexão estético-existencial de Roberto Michel, o protagonista cortazariano, que aponta o limite entre o objeto representado e o sujeito representante, entre a vida fotografada como objeto de observação "limitada" e a subjetividade que se exprime na "eleição/seleção", poderemos dizer, de um fragmento de vida: "je vis alors une micro-expérience de mort: - escreve Barthes - je deviens vraiment spectre" (p. 30).

Deste modo, a foto pode declarar a sua outra essência, "révéler ce qui était si bien caché que l'auteur lui-même en était ignorant ou inconscient" (p. 57) e mostrar "le punctum", sempre segundo a bela terminologia de Barthes, "la 
piqûre, le petit trou, la petite tâche, la petite coupure, et aussi le coup de dés. Le punctum d'une photo, c'est ce hasard qui, en elle, me point (mais aussi me meurtrit, me poigne)" (p.49). Revelar o que resta oculto é quase um estado de graça que é concedido somente ao fotógrafo, entre todos os artistas, nessa perspectiva (ou, talvez, poderemos dizer, no seu "clique") reside a possibilidade de uma leitura da realidade que possa superar o binarismo torpe da contraposição real versus imaginação.

No discurso fotográfico, no diálogo com a literatura, se oferece ao observador um desdobramento da realidade, não no sentido de uma fragmentação destrutiva, mas de uma "vacilação" da realidade, enquanto se "traumatiza" a fronteira do déjà $v u$, daquilo que aparece como já conhecido, de tudo aquilo que é catalogado como antiquado, passado, sem mais marcas de valor para o presente. Assim, a fotografia (embora pudéssemos referir-nos a qualquer outra imagem, no sentido de um sinal ilimitado de significação) sugere, repetidamente, outro significado. Barthes, com muita propriedade, sustenta que, superando o contingente, como por outro lado sucedia com outros discursos estéticos relacionados à imagem, a fotografia se revela "subversiva", um produto efetivamente "transgressivo", porque desobedece às leis de uma realidade contemplada como imobilidade. Trata-se, nesse caso, de uma subversão surpreendente, porque, observando reiteradamente o fotógrafo descobre um novo "valor agregado" a isto que parece aparentemente inócuo e previsível. Barthes define este tipo de fotógrafo-artista, como um "acrobata": "(il) doit défier les lois du probable et même du possible".

De fato, a probabilidade e a possibilidade, atributos que só uma visão restrita e exclusivamente empírica da realidade elimina como exemplos inelutáveis do conhecimento, despertam a realidade porque desta última ampliam, mediante a fantasia, a sua reprodução. Entretanto, a amplidão que restitui a vida a uma pequena tela, a um pequeno retângulo no qual o passado parece estar congelado, transforma o noema originário da fotografia em um ato comunicativo presente. Em outras palavras, aquilo que Barthes chama "noema" fotográfico (ou seja, aquele inegável "ça-a-été”) se abre, na experiência literária, a uma nova dimensão da configuração da história (e do tempo, naturalmente), pois este "ça-a-été" se transforma na dramática constatação de "ça-y-est-encore". Porém, diferentemente da leitura "melancólica" de Barthes, estamos convencidos que a fotografia, ou a imagem, ou qualquer outra 
representação que mova o sujeito até a constatação do presente, não se baseia somente em sua memória passiva de alguns acontecimentos passados, mas numa "comemoração", isto é, na celebração da consciência de um "ça-a-été", que, porém, vive de qualquer modo, provocando um efeito, conseqüentemente, inesperado e, por assim dizer, "escandaloso". "La photo possède une force constative, et [...] le constatif de la photo porte, non sur l'objet, mais sur le temps. D’un point de vue phénoménologique, dans la Photographie, le pouvoir d'authentification prime le pouvoir de représentation" (pp. 138-139). A foto, de certo modo, permite a dilatação temporal, prometendo ao próprio tempo uma modalidade "excessiva", "monstruosa", inatual. O fotógrafo-intérprete capta o aspecto narrativo da fotografia que supera o historiográfico, isto é, aquele tipo de vida que parece morte (porque não é mais) e que está atrás da moldura retangular da foto revelada. É, em outras palavras, a alegoria do mito de Perséfone que aqui persiste, na obra artística. Por isso, "a fotografia deve ser lida" , pois, como propõe Ottmar Ette: "L'image et le texte forment une unité dynamique indissoluble, dont la résolution est toujours reportée, productrice constante de textualités nouvelles" (Ette, 1996, p. 38).

A fotografia, o uso semiótico das imagens, o texto-base (textum) enriquecido de seu poder polissêmico, são todos fatores das catarses porque não permitem mais uma "simples" observação da realidade, mas oferecem uma perspectiva mais inteligente, que modifica o automatismo trivial com o qual olhamos os objetos, as pessoas, as paisagens, o pequeno ritual cotidiano. Também a trivialidade da morte, que a escrita traz consigo, é desconstruída, porque a presença da morte é símbolo daquela cotidianidade que é capaz de observar.

Nesta direção, o cotidiano se transforma em algo de novo, se despindo de seu caráter ordinário e se des-familiariza, para usar a expressão de Viktor Shklovski (otstranienie). Assim o que é familiar se torna pelo efeito da fotografia (e deveremos acrescentar: pelo efeito, também, da literatura) obscuro, oculto, dissimulado. O leitor e o observador participam deste evento desfamiliarizador. Porém, ao mesmo tempo, mediante a sua participação, o leitor e o observador mantêm a própria função específica de medium. Trata-se de uma mediação que confirma a alienação, como sustenta Sontag, do sujeito. Alienação, neste caso, é sinônimo de alteridade, de ser estranho, do ser outro de si, uma alienação que o sujeito poderá resolver somente na consciência da aporia dada do significado incompleto da realidade. 
A "Elegia de Maria Teresa" possui um conjunto de figurações de morte como a doença, a ausência, a distância. A fotografia, achada por casualidade, é a ocasião de um gesto habitual ou ordinário de se des-familiarizar. Há, mais além dos marcos da fotografia contemplada e poetizada, uma força misteriosa, um alongamento dos limites da existência que a poesia detecta e permite. Essa "tentativa de fixar o instante em diálogo com a fotografia" (Alves, 2008, p. 238) se acompanha, na estética beliana, das loucuras do quotidiano: a percepção do drama para com Deus; o sentido constante da finitude das coisas e da própria vida; a busca incessante de uma "graça" que possa coincidir com a Palavra:

Conheço outros retratos teus onde também estás viva

(...) nesse verão bretão onde então procurava

justificação por mínima que fosse para a vida

numa das muitas fugas de mim próprio

(...)

de que só pela morte enfim me encontrarei comigo

com todos quantos verdadeiramente amei

alguns desconhecidos e alguns mesmo inimigos

sobretudo sedentos de justiça

de que depois somente de bem morto hei-de dispor daquela paz

que sempre apeteci mas nunca procurei

até por não ter tempo para isso nem sequer para saber

coisas simples como saber quem sou porque ao certo só sei

que muito mais passei naquilo em que fiquei

A fotografia beliana, que abre a reflexão do poeta, pode ser lida via Roland Barthes. Para o crítico francês a instantânea é uma verdadeira e própria "loucura/demência", una loucura que apanha vigor graças à sua instância conotativa: o objeto representado é já existido, agora mesmo não é mais, é "morte", ausência, rasgão, sacrifício. Porém, este mesmo objeto está lá, onde neste momento o vejo. Era, estava, mas o percebo "neste momento":

C'est ici qu'est la folie; car jusqu'à ce tour, aucune représentation ne pouvait m'assurer du passé de la chose, sinon par des relais ; mais avec la Photographie, ma certitude est immédiate : personne au monde ne peut me détromper. La 
Photographie devient alors pour moi un medium bizarre, une nouvelle forme d'hallucination : fausse niveau de la perception, vraie au niveau du temps [...] : image folle, frottée du réel (Barthes, 2002, p. 177).

A grande revolução que Barthes percebeu em relação à polaroid, à instantânea é que essa desestabiliza a ética, isto é, desestabiliza a "alegria" (e com essa também a alegria erótica, a jouissance) que passa através da imagem. Entretanto, Barthes avisa que "généralisée, elle [la photo] déréalise complètement le monde humain des conflits et des désirs, sous couvert de l'illustrer" (Barthes, 2002, p. 182. Grifo meu).

A fotografia se converteu numa proposta de simulacro sagrado, uma imagem do sagrado, ícone da "memória", no sentido de um passado que continua vivo e um presente determinado, circunstanciado. A imagem, por isso, vivifica a esperança do escritor, tentando superar a presença enfadonha da atualidade existencial, reintroduzindo-se na realidade passada, como por meio de um "sacrifício". A memória e a imagem tornam-se, assim, operações textuais essenciais e permitem ao texto (e à foto) acumular-se num arquivo de materiais cotidianos, que a literatura se encarrega de fazer vir à luz.

Contudo, a literatura de Ruy Belo se encarrega de abrir buracos, desvendar vazios, em uma experiência liminar porque a memória da fotografia sempre fala a partir de um objeto que não é mais, isto é, a partir de uma experiência de morte. A memória vincula-se, assim, à experiência do trauma. A consciência do poeta é a impossibilidade da representação do detalhe, do rasto da morte. Se a morte é aquele Indizível, que a literatura faz "dizível", então, "a poesia é um especial discurso mortal, porque figurando e ficcionalizando essa experiência total da ausência, consegue fazer ver sua presença em abismo" (Alves, 2008, p. 249). Assim, a morte permite dizer e a poesia permite ver. É bastante sedutor e interessante repensar a proposta de Roland Barthes, segundo a qual a foto seria mais próxima do teatro que da pintura: "La Photo est comme un théâtre primitive, comme un Tableau Vivant la figuration de la face immobile et fardée sous laquelle nous voyons les morts" (Barthes, 2002, p. 56). Um teatro de sombra, de morte, mas também, e talvez por isto, um teatro de retratos e recordações.

Os retratos lembrados na lírica de Ruy Belo se transformam lentamente em pessoas (sonhadas? já desaparecidas? mortas?) que se movem como marionetes que o observador vê com o desejo de tê-los sempre presente. Tal- 
vez, nem sempre. Mas se trata de uma modalidade de sublimação da morte. Como é uma obrigação para com a morte qualquer poema autêntico: ("teve de inventar pra conquistar essa metáfora ... eu estarei morto e pouco poderei fazer / por ti simples mulher da minha vida"). Em um tocante ensaio sobre a música de Johann Sebastian Bach em Manuel de Freitas, Pedro Eiras propõe uma leitura da poesia como paradoxo da sua ineficácia para não responder às angústias do mundo:

O poema não é a descoberta de um sentido; ou talvez: o poema é a desistência da descoberta de um sentido que cada verso promete e perde; ou ainda: o poema é apenas a encenação da desistência da procura de um sentido que, apesar da própria retórica de auto-anulação, insiste em existir (Eiras, 2007, p. 187).

Como a poesia, também a fotografia encena uma desistência. A fotografia que, nessa lírica de Ruy Belo, é um impossível "presente em mim como ninguém", o Tu que faz apreender "a forma de convívio com o meu cabelo ralo", se ofusca pelas lágrimas ("deste molhado olhar de homem que morre / e se comove ao ver-te assim presente tão subitamente"). A fotografia representa, portanto, um tableau vivant onde, escandalosamente, é possível fazer a experiência de observação da morte: é um pouco, como diz Marguerite Yourcenar ao velho imperador Adriano, "entrar na morte com os olhos abertos". A fotografia permitiria, portanto, uma misteriosa comunicação com as questões mais íntimas da existência. Ela é uma estratégia para poder "parar" em detalhes o mundo visível, mas ao mesmo tempo, se revela como uma janela aberta para seus modelos inconscientes que fixam os instantes transitórios e iludem sobre o desesperado retorno deles. De fato, para Walter Benjamin, "somente a fotografia revela este inconsciente ótico, como somente a psicanálise revela o inconsciente pulsional" (1985, p. 94). Poderíamos acrescentar que também a poesia revela aquela "sensação de incompletude e catástrofe que marca nossa humanidade" (Alves, 2006, p. 141). A palavra poética de Ruy Belo fala de "lacunas", mas também de "tempo" e "morte". É uma palavra que, como reconhecia o próprio poeta vence o tempo, pois "essa luta contra o tempo configura o narrar, move a arte e determina a poesia como especial memória do sujeito, gesto rebelde de não submissão ao (...) destino de morte e esquecimento eterno" (Alves, 2006, p. 148). 
É nesse cruzamento de vazios e lacunas que literatura e fotografia parecem se tangenciar. A "estranheza" da fotografia é a mesma do discurso da literatura: recordar paradoxalmente tanto a presença quanto a ausência, um tempo misterioso, um "para sempre", que se une indissoluvelmente à lembrança. Blanchot assim lia o quid da imagem fotográfica, que podemos confrontar com a proposta do fazer poético:

A essência da imagem é estar toda fora, sem intimidade, e no entanto mais inacessível e misteriosa do que o pensamento do foro íntimo; sem significação, mas invocando a profundidade de todo sentido possível; irrevelada e todavia manifesta, tendo essa presença-ausência que faz a atração e o fascínio das Sereias (Blanchot, apud Barthes, 1984, p. 157).

A fotografia capta o que o olho humano não consegue registrar normalmente. Trata-se de um escândalo, de uma transgressão, para que, à visão do observador - sempre aproximativa, mas necessária - se substitui uma batalha com o imponderável. A fotografia é um acontecimento surpreendente. E é sempre um acontecimento familiar e cósmico ao mesmo tempo, como lemos na poesia de Ruy Belo.

Ruy Belo introduz uma voz tão peculiar nas letras de língua portuguesa que deixa seus rastos na poética de autores contemporâneos. Trata-se, como escreve Rosa Martelo, de uma poesia da ausência:

Uma linha de escrita que se caracteriza por tematizar o mundo contemporâneo sob um olhar intensamente marcado pela perda. A esse olhar, tudo evidencia uma condição de pobreza, de falta, ou de falha com a qual a linguagem entre em sintonia ao usar de grande parcimônia na evidenciação de sinais de poeticidade, assim se produzindo um efeito de transparência discursiva (Martelo, 2008, p. 291).

Este olhar que se metamorfoseia em uma "transparência discursiva" é filtrado, na "Elegia de Maria Teresa", de Ruy Belo, pela alegoria da fotografia que atua profundamente no discurso poético, ressuscitando uma "falação", em lugar do silêncio, e uma contemplação, que, paradoxalmente, a ele equivale. 


\section{Referências Bibliográficas}

ALVES, Ida. "Ruy Belo e a errância na linguagem: figurações e ficções da morte". In: Parreira Duarte, Lélia (org.) De Orfen e de Perséfone. Morte e literatura. São Paulo : Ateliê - Belo Horizonte : Editora PUC Minas, 2008, pp. 235-252.

ALVES, Ida. "Fugitivo da catástrofe: a escrita poética de Ruy Belo". In: Parreira Duarte, Lélia (org.) As máscaras de Perséfone: figuraçoes da morte nas literaturas portugesa e brasileira contemporâneas. Rio de Janeiro : Bruxedo - Belo Horizonte : Editora PUC Minas, 2006, pp. 135-150.

BARTHES, Roland. La chambre claire. Note sur la Photographie. Paris : Gallimard-Seuil, Cahiers du Cinéma, 2002.

BELO, Ruy. Obra poética. Lisboa: Presença, 1984 (vol. III).

BELO, Ruy. "Elogio de Maria Teresa". In: Todos os poemas. Lisboa: Assírio \& Alvim, 2000, p. 330.

BENJAMIN, Walter. Pequena história da fotografia. In: Obras escolbidas. Vol. I. São Paulo: Editora Brasiliense, 1985.

BENJAMIN, Walter. A obra de arte na era de sua reprodutibilidade técnica. In: Obras escolbidas. Vol. I. São Paulo: Editora Brasiliense, 1985.

EIRAS, Pedro. "Meu deus de brincar somente... Bach na poesia de Manuel de Freitas". In: Cadernos de literatura comparada. Poesia e outras artes do modernismo à contemporaneidade, Porto: Universidade do Porto, n. 17/2007, pp. 177-194.

ETTE, Ottmar. "Barthes-photo: réflexions sur le lieu de l'écriture", In: Lendemains. Tübingen 1996, vol. 21, n84, pp. 28-38.

JAMESON, Fredric. Signatures of the Visibile. New York: Routledge, 1990.

MARTELO, Rosa Maria. "Alegoria e autenticidade (a propósito de alguma poesia portuguesa recente". In: Subjetividades em devir. Estudos de poesia moderna e contemporânea, Célia Pedrosa-Ida Alves, orgs. Rio de Janeiro, Sete Letras, 2008, pp. 291-303.

PARKINSON ZAMORA, Lois - Faris, Wendy B., eds. Magical Realism: Theory, History, Community. Durham: Duke University Press, 1995.

SONTAG, Susan. On Photography, London: Penguin Books, 1977. 